\title{
To be Myself and have My Stealthy Freedom: The Iranian Women's Engagement with Social Media
}

\section{Gi Yeon KOO ${ }^{1}$}

Research Fellow at Institute of Cross Cultural Studies, Seoul National University, Seoul kikiki9@snu.ac.kr

Recibido 17/05/2016. Revisado y aprobado para publicación 18/12/2016.

Para citar este artículo: "To be Myself and have My Stealthy Freedom: The Iranian Women's Engagement with Social Media" en Revista de estudios internacionales mediterráneos, 21, 141-157.

Para acceder a este artículo: http://dx.doi.org/10.15366/reim2016.21.011

\begin{abstract}
The objective of this research is to explore the development of digital social and social movements at the local level through Iranian women's engagement with social media. In this article, I delve into the cultural and social background of a Facebook page named "My Stealthy Freedom" and the practices of "cyber feminism" in Iran through an anthropological perspective. This online movement finds its value in that it has become a new platform for the women to raise their voices in public online sphere about their human right and freedom. By examining the online and offline discourses about Iranian hijab policy, I aim to understand how Iranian society is creating new spaces for the formation of public discourse.
\end{abstract}

\section{Keywords:}

My Stealthy Freedom, Facebook, Social Media, Hijab, Iran.

\footnotetext{
${ }^{1}$ This work was supported by the National Research Foundation of Korea Grant funded by the Korean Government (NRF-2013S1A5B5A01030162).
} 
Some try to remind us over and over again that the freedom that is stealth cannot be called freedom at all. Yes, it is true! And nothing could have revealed it to the world in a better way than all the photos and women's words on this page.

These stealth moments of pleasure are not called FREEDOM.

So what is the significance of this coming together on this page? The reason is exactly to show that our share of freedom in Iran is STEALTH. These stealthy acts will challenge the absence of freedom, when revealed.

Excerpt from the caption under the cover photo of "My Stealthy Freedom"

\section{Introduction}

The objective of this research is to explore the development of digital social and political movements through the ethnographic case study of the Iranian women's movement's engagement with social media. By examining the online and offline discourses regarding the Iranian women's use of the hijab, I aim to understand how social media in Iranian society is creating new spaces for public discussion. Social media refers to the communication between users, who share their opinions, perspectives, and experiences with one another over an open media platforms. A majority of feminists deem online space as a system that weakens the structure of sexism. Sadi Plant (2000) maintains that women feel relatively greater freedom in the online environment of social media than elsewhere. In online space, they enjoy the freedom to change their identities and maintain anonymity, giving them the "secretive" thrill of freedom from repression by the censored national media environment and unequal gender structure, and allowing them to participate in online debates alongside men. Women are using the Internet and social media more actively than any other social group to address problems regarding gender roles and conventional patriarchal practices (Sreberny 2015:358-359), and their conative use of new technology has even been named "cyber feminism" (Karimi 2014: 225-226). "Cyberfeminism" is a concept put forth by Donna Haraway which judges scientific technologies such as cyberspace as utopian, tearing down gender binaries (Haraway 1991).

Facebook provides a "non-anonymous" environment where women may reveal their "true and honest" selves (Hajinejad 2010:25). Thus, it can be understood that Facebook's "anonymity" encourages them to be more sincere in their expressions to the outside world (Hajinejad 2010: 11). Recently social media such as Facebook and Twitter has been widely employed all over the globe in large scale political activities (Loader and Mercea, 2011; Van Laer and Van Aelst, 2010). Loosely connected online communities are now capable of carrying out group activities. Lately many researchers have emphasized that new medium including social media frees participants from being limited by traditional media (Bekkers, Beunders, Edwards and Moody, 2011; Garrett, 2006; Scott and Street, 2000; Harlow and Harp, 2012). In other words, Facebook pages have shown however loose they are connecting the domestic and the international environments and that they have a possibility for growth as a social activism tool.

The Iranian women's Facebook page "My Stealthy Freedom" thus presents a fitting ethnographic case for examining these developments. The page was started by a female journalist from the

\footnotetext{
${ }^{2}$ Cover photo posted on May 19, 2014

(https://www.facebook.com/StealthyFreedom/photos/a.858877157459713.1073741827.858832800797482/8711011 86237310/?type=3\&theater)

142
} 
Iranian diaspora in England, and it has since gained many global supporters including English and French translations of posts in Persian. Moreover, it is gradually expanding the scope of its critical subject matter beyond the compulsory use of the hijab, to issues of gender discrimination against women as well as that of the governmental and religious controls over emotions. Since the 1979 Islamic Revolution in Iran, all women over nine years of age have been required by law to wear the head covering known as the hijab in public areas. While the majority of the population is Shi'a Muslim, the opinions of Iranian women regarding the regulations enforcing the wearing of the hijab vary at the local level. Regardless of such a dispute, in current Iranian society, wearing the hijab remains an indisputable imperative and not wearing the hijab properly may lead to legal prosecution.

This research however, focuses on the specificity of contemporary Iranian women's use of such social media platforms as Facebook/social media, not on the broader social movements which have emerged in resistance to the 37-year-old hijab policy. In particular, I analyze the Facebook page "My Stealthy Freedom," where women post pictures of themselves without their hijabs and share their stories. Although "My Stealthy Freedom" has been gaining much notoriety in the press and academia (Hamzehei 2014; Karimi 2014; Khiabany 2015; Koo 2014; Lewis 2015; Novak \& Khazraee 2014; Sreberny 2015), the voices of women as subjects has been missing in these studies. It is this void which I seek to fill, by connecting women's online participation with developments in the offline social movements in Iran.

This article presents a qualitative analysis of the Facebook page drawing from a background of anthropological fieldwork in Iran. My research will be supplemented by qualitative interviews with Iranian women, in order to present a more comprehensive view of the cultural and social contexts surrounding the phenomenon of online social movements. By analyzing the posts and comments on this page, I seek to understand the motivations and concerns of the women's social movement on social media. Despite the fact that Facebook has been officially blocked, Iranian women are aware of the page's existence and they show a potential for change through daily practices. For example, they post symbolic photos of themselves wearing their hijabs loosely, participate in movements for the freedom of travel and of riding bicycles. In addition to such an online analysis, I have carried out primary ethnographic research on women's issues and political participation on social media, through a year-long period of field work in 2009 and two short-term fieldwork visits in January 2015 and January 2016, to examine how social movements are interacting with offline reality. My online and offline interviewees were largely reformative and secular women of middle and upper class background in their 20s and 30s, living in large cities like Tehran, Isfahan and Shiraz. They usually do not wear conservative hijab like the chador and they do not typically wear hijab in front of men who are not related to them while meeting with them privately. My other interlocutors are men and women varying widely in age range whom are not traditionalists and are largely against Islamic policies, including the hijab policy. Thus the views and the examples discussed in this study do not reflect the views of political conservatives or traditionalists, nor do they necessarily represent the sentiments of the majority of the Iranian population.

Analysis of social media movements critical of the government's hijab policy is a gateway to understanding the major social issues faced by contemporary Iranian society. Despite the visibility of social movements on social media, the perception and implementation of the hijab in offline reality still follows extremely conservative and traditional standards. Thus, once again, we see that the hijab transcends a mere Islamic garment and is, in itself, political and plays the role of a political symbol. Exploring women's online social movements, a central practice of which is to 
share photos of women removing their hijabs through social media, is key to understanding such controversial issues in contemporary Iranian society, and it is in this that the value of this research paper lies.

\section{Iran's Digital Environment and Women's Social Movement}

Research on social media in the Middle East and North Africa (MENA) region has received much attention, in particular in relation to regional democratization movements like the 2009 Iranian Green Movement or the 2011 Arab Spring (Khiabany 2015: 348; El-Nawawy \& Khamis 2013). These two events have marked the onset of digital activism in the MENA region to such an extent that they have been called the "Twitter Revolution" and "Facebook Revolution." With the onset of democratization in 2009, there has been increasing interest in political participation on social media platforms such as Twitter, Facebook, and YouTube (Akhavan 2013; Rahaghi 2012; Sreberny \& Khiabany 2010). Furthermore, since 2000, the desire for media and social reform has greatly altered Iranian mass culture. Once again, it is the women and young people that are leading social change through mass culture and new media (Sreberny \& Torfeh 2013). The Internet is becoming a "sphere of the political," as it provides a convenient environment for the political participation of women (Sreberny 2015:357). In a recent paper, Sreberny discusses women's digital activity in the MENA region. Most women-related issues of the MENA region are discussed online not only in Arabic, Persian, and Turkish, but also English and French, which shows the importance of a "Middle Eastern diaspora" in the United States and Europe in the development of such phenomena. Thus, behind every social movement in the MENA region, we find a network of global, regional, and national entities supporting it.

As Khiabany (2015) points out, the positive response to social media websites in Iran is closely related to the civil movements that have been brewing in the bases of Iranian society since the 1990s. I seek to explore the trends in the Iranian social movements centered on women, who are the protagonists of contemporary Iranian reformist movements and civil society. It would not be an exaggeration to say that modern Iranian history is but an endless series of social movements and revolutions. Social movements have been developing around women, cultural figures, journalists, students, intellectuals, and religious organizations. As Lerner argues, "after the 1997 election of Khatami, the environment has proven increasingly difficult for reformist or dissident voices on the Internet (Lerner 2000:562) ". President Khatami brought reformative movements to the core of political debate, and as a result, under this idea, politicians, intellectuals, and journalists started gathering. Women and youth, whom have been the greatest supporters of President Khatami's reforms, also joined them (Semati 2007; Yaghmaian 2002). Thereafter, Iranian society began to make social demands for the opening to the international market, which would light the fuse for the large-scale democratization movement in 2009, 30 years after the Islamic Revolution.

In particular, since the 1979 Islamic Revolution, women and youths have been at the center of much controversy amidst strengthening and changing Islamic cultural policies (Bayat 2005, 2013). As they lead reforms and change in Iranian society, they are also those that enter into the greatest conflict with the conservative Islamic government. Taking into consideration such a particular social environment, it may be difficult to understand the movements of the Iranian women and youth as social movements. Under the current situation of hardline control and regulation it is difficult for these two groups to seek systematization and solidarity. 
Bayat (2005) emphasized this loose solidarity as 'imagined solidarities'. He proposed that this 'imagined solidarities' explained "modes of solidarity building in closed political settings" of Iran. Bayat announced that "An 'imagined solidarity' is, thus, one which is forged spontaneously among different actors who come to a consensus by imagining, subjectively constructing, common interests and shared values between themselves"(Bayat 2005). According to this argument, the actors of "My Stealthy Freedom" are participating in social social movement by merely posting on Facebook pages, liking them and reading them. However, the passive network forming between such disorganized individuals is threatened by the government. Their solidarity, though still very loose, was one of the most important social resources that made the 2009 Green Movement possible. But at the same time, Iranian women's activism was repressed like never before during the 2009 Green Movement. Iranian regime regarded that "Women's struggle for gender equality and self-expression" was at the core of Green Movement. Thus as the aftermath of Green Movement, women activitsts were exiled or forced to go into hiding (Bayat 2013: 103-105). It is in this context that online social movements such as "My Stealthy Freedom" are an extension of the offline democratization movements prior to 2009 and of the Green Movement of 2009.

Let us explore the role of the Internet in Iranian society before the onset of social media. According to Lerner (2010:561), in 1999, "the Internet played only a limited role in widespread student protests Iran. Primarily, the web was important because it helped students keep in contact with each other even after government crackdowns made it impossible to meet publicly. This more closely conforms to the idea of the Internet as a setting for the planning phases of Islamic activism actions." Lerner argues that the 2003 student's protests show that the Internet was used actively by anti-government elements to stimulate followers and arrange them for public demonstrations.

In the early days of the new millennium, the blogosphere dominated Iran (Alavi 2005). Post 2009, this dominance was handed over to social media. Numerous studies have documented that social media and cyber activism started their climb to power after the presidential election of Iran and the Green Movement (Yahyanejad 2015, Faris and Rahimi 2015). As Akhavan argues, "the social media mobilization that took place in the wake of the disputed Iranian election of 2009 seemed to confirm optimistic readings of the new technology as a Twitter Revolution (Akhavan 2013: 83)." In spring of 2009, Iranians and especially diaspora reformist activists living outside of Iran used social media to support their favorite presidential candidates (Yahyanejad 2015:167). In January 2009 the Iranian government stopped blocking Facebook and Twitter, and within a month Facebook became the fifteenth most visited website in Iran. In Iranian society, social media including Facebook has been hailed and fueled by the resisting groups: the progressive political supporters with reformist tendencies, educated women, upper and middle class youth living in urban areas and the queer communities of Iran (Faris and Rahimi 2015). Specifically, the relationship between women's education and use of Facebook and civic participation offline is very notable. This correlation appears to be due in part to "the informational structure of Facebook that allows educated women to engage with subversive expressions and seek the Internet as an alternative platform for connection and communication" (Eloranta, Kermani and Rahimi 2015).

Facebook is not just a form of mere social interaction for these women. It is a battle ground for normative discourses like maternal instinct and womanhood to come head to head (Gheytanchi 2015). Women are now able to find each other all over the globe, and share their thoughts with each other. Gheytanchi $(2015,52-53)$ also points out that one must be cautious not to overestimate liberating cyberspace freedom and its power because most Iranian women are still 
tightly bound to an oppressive offline reality and such utopia-like virtual space does not exist. However, it cannot be overlooked that social media such as Facebook does operate as a type of public space that permits women's voices.

Benhabib (1992) argues that the negotiated sociality of the public sphere is situated in political issues and space is characterized by practices and actions. Benhabib develops Arendt's (1998) concept of the public/private spheres, and argues that "a public space emerges whenever and wherever men are in concert." She also argues that "these diverse topographical locations become public spaces in that they become sites of power, of common action coordinated through speech and persuasion." From Benhabib's perspective, the Iranian online sphere is not only virtual but also functions as a public space. This theoretical position explicates how the public in Iran is constituted in the virtual spaces. Shirky (2011) argues that social media creates a 'shared awareness', "the ability of each member of a group to not only understand the situation at hand but also understand that everyone else does, too". In other words, social media, as an instrument of communication between friends and colleagues, allows for the "second step" in the formation of political opinion. As Shirky (2011) argues that "more promising way to think about social media is as long-term tools that can strengthen civil society and the public sphere", we can expect social media to be the cornerstone for the development of an alternative public sphere. This study therefore examines the role of "My Stealthy Freedom" on Facebook within the Iranian women's right movement, and what purpose it serves as a virtual but also public space for debate.

\section{An ethnographic analysis of "My Stealthy Freedom"}

In this section, I address in detail women's activity on new social media, focusing especially on the Facebook page "My Stealthy Freedom" in order to make sense of the meaning for Iranian society conveyed by the messages of this online movement. For such purposes, I will analyze actual postings and comments to explore the significance of this online social movement and its potential to develop into a social movement at the local level. As mentioned above, "My Stealthy Freedom" was created in 2014 by an England-based journalist from the Iranian diaspora, and has since then received over 924,000 "likes," becoming a hot issue both in and out of Iran. By addressing the lack of "freedom of choice" regarding the hijab policy, it has gained the attention of many Iranian researchers (Hamzehei 2014; Karimi 2014; Khiabany 2015; Koo 2014; Lewis 2015; Novak \& Khazraee 2014; Sreberny 2015).

The following is a translation of the message that greets visitors to the home page of the "My Stealthy Freedom" website:

"This page does not belong to any political group and the initiative reflects the concerns of Iranian women, who face legal and social restrictions.

All of the photos and captions posted have been sent by women from all over Iran and this is a site dedicated to Iranian women inside the country who want to share their "stealthily" taken photos without the veil.

For those of you non-Persian speakers, this article fully explains the creation of the page "Stealthy Freedom of Iranian Women" and the demand of Iranian women who have shared their picture and their words with the world.

The excerpt above belongs to the caption of the cover photo of "My Stealthy Freedom." When this page was first made, women started to show "stealthy" photos of themselves in rather deserted places without the hijab, taken from the back or in profile. With time, women began to reveal their faces and it is notable that recent photos are much more 
daring than their predecessors. There are photos of women walking in the streets with their veils in hand, or videos of women walking with their veils pulled down to their necks. Some examples of the captions accompanying these photos include statements like "What seems more natural?", "Let me be who I am," or "I never insulted or hurt anyone, so I ask everyone to do the same. Don't hurt me and don't insult me. Please respect me and how I want to live."

The social message these women are conveying through their posts on "My Stealthy Freedom"' did not just suddenly arise with the emergence of this Facebook page. It is the extension of a long, previously private debate regarding the 36 years of institutionally imposed hijab that has finally reached the outside world through the platform of social media. In this globalized, online environment, women are slowly, and carefully, expressing their thoughts about themselves and their hijab in public. In other words, these women, who are "liking" this Facebook page or revealing themselves on it, are refusing to remain anonymous under a hijab, and are willing to rediscover their selves. In response, the Islamic administration is accusing the act of showing one's colors and raising one's voice as being a dangerous act of sexuality and is repressing it strongly. Despite this social and political context, women are still courageously posting photos of themselves without their hijabs, accompanied by messages that demonstrate their desire for freedom. According to my interlocutors, most of the people who are courageously posting photos of themselves on Facebook without their hijabs, accompany their posts with messages emphasizing that raising one's voice is a dangerous act online. Furthermore, with the recent completion of negotiations regarding Iranian economic sanctions, and the consequential Iranian people's hope for the return of the rogue nation to the international stage, the voices of the Iranian women are being raised even more frequently. In fact, since April 2016, there have been more than two thousand posts on the timeline of "My Stealthy Freedom," and three or four photos posted every day.

Case 1: From a post from "My Stealthy Freedom"

1. Regulations on dress codes will not succeed, neither by the enforcement of religious police nor through the imposition of fines. I want the freedom to choose for myself. I want the freedom to choose my own clothes. I want to live freely, with my own principles and beliefs.

2. It is an ecstatic feeling to have the wind run through your hair under the blue sky. We are living under many restrictions. Is there anything more important than asking to have the same rights as men to live under the wind, rain, and sun, for at least a moment?

On this page, in addition to the photos women post in resistance to the hijab policy, there are also articles and commentaries by the Iranian journalist Masih Alinejad:

"When somebody asks you whether your only current concern is the hijab, take a look. If that person is a man, then put a scarf over his head and tell him to wear it for thirty years and then come back to talk about your concern. If he doesn't want to wear the scarf, force it on him so he can get a taste of the pressure. If a woman wearing the hijab voluntarily asks you whether all of the problems of this country are solved except for hijab and tells you that we have bigger concerns, then take off her hijab and tell her to be without a hijab 
forcefully, so she can see how painful it is to have to wear hijab by force. When somebody forces you to take off or to wear clothes, then fixing your clothes becomes your primary concern before attending to other functions.

If a woman who doesn't believe in the hijab asks whether a headscarf sums up all of our concerns and adds that we have to fight for more major freedoms, tell her: "No dear, this is not the sum of all of my concerns, but it's the first step to walk through the darkness. Instead of fear, indifference or cursing at the darkness, it's better if each of us lights a candle. And even if you don't personally light a candle, don't put out my candle, because each one of us completes the other one. The right to choose one's clothing is the first step, because since the age of seven they have robbed us of our identities and forced us to live with a dual identity."

As Alinejad emphasized, despite the fact that social movements on social media have yet to impose significant resistance in the offline public sphere, they are, according to these women, a sort of "candlelight" that lights up the darkened hearts of the women seeking social reform, who are oppressed by the government and social regulations.

As mentioned before, in July 2015, Iran experienced a historical turning point, as the negotiations on Iranian economic sanctions were finalized. The United Nations had passed economic sanctions in 2008 when Iran refused to suspend its nuclear enrichment program, which had incited suspicion of nuclear weapons development. The international society, led by the United States, had blocked all activities that led to Iran's energy development and oil refinery production. After years of negotiations, these sanctions have finally been lifted, and Iran has been invited back to the international arena, but its social, political, and human rights issues such as the compulsory enforcement of the use of the hijab on women remain a task to be solved.

Case 2. A posting from "My Stealthy Freedom" posted July 15, 2015

“The agreement was reached today. But I'm not happy.

This is my letter of pain and sorrow:

I was a 22-23-year-old girl . . . I had recently graduated from university and the most important decisions of my life were on the way ...

Happy and carefree, I couldn't keep my feet on the ground . . I couldn't contain my heart from the excitement of achieving my wishes and dreams and my mouth watered thinking about the sweetness of reaching them...

But today I am a 34-year-old woman . . . I think about the days that passed by for my generation and I, while we yearned for the minimum . . . I think about the days that could mark the most beautiful moments in my life, but . . . 12 years of continuous endeavor to reach the minimum standard of living, the standard as defined by statistics . . 12 years of sleeping with open eyes, hoping that if life didn't become heavenly tomorrow, at least it wouldn't turn into a worse kind of hell ...

But today the agreement was reached ... It's as if my feelings have been numbed by anesthetic drugs, I don't even know how I should feel or react?! 
I only think about the fact that those who were able to reach an "agreement" today, could certainly do the same thing 12 years ago ... But my generation and I can no longer go back to those days ... Now it's us and the "dreams gone with the wind."

The issue of women's rights in Iranian society cannot be simply defined as a conflict between men and women, or a result of men's hatred toward women. In July and August 2016, people started using the hashtag \#meninhijab on the "My Stealthy Freedom" page to upload photos of men wearing hijab, instead of their wives, daughters or mothers. Men in hijab stood next to women without hijab to deliver the following message:

"We hope that one day in every family all members will respect each other's individual freedom ...We do not believe that forcing someone to wear compulsory hijab is a sign of honor for a family. Please join the challenge and stand with women of Iran. In stilling a culture of respect starts in the family. This is one of the most beautiful photos that My Stealthy Freedom had received as part of \#MenInHijab campaign thus far."

While it is true that Islamic conservatives retain their perspective toward the female body and emotions as a potential threat to the community, this issue involves gender considerations as well as considerations of individual liberties, freedom of expression, and human rights. In other words, "My Stealthy Freedom" is not only a page that calls out for the gender equality rights of women, but it is a page that calls out for basic human rights. For example, August2016 Iran's supreme leader Khamenei declared it haram for women to ride bicycles in public, and women fought against this fatwa with the hashtag \#IranianWomenLoveCycling on this page(Sheikhi 2016) . In Iran Facebook is "officially" forbidden, for which accessing the page itself is a direct, and therefore dangerous, act of resistance and rebellion against the Islamic government. Nonetheless, it is through this page that Iranian social movements have been able to raise awareness of the problems facing Iranian society and increase their exposure.

As mentioned previously, one of the most important characteristics of this Facebook page is that it directly raises the issue of the hijab policy, but it is now also expanding its scope to cover various women's rights issues, such as the restrictions on women raising their voices (singing in public), entering stadiums, or traveling without their husband's permission. For example, there was a period when women posted videos of themselves singing, in protest against the criminalization of women singing onstage. In this way, "My Stealthy Freedom" holds strong symbolic power as a site of criticism toward the compulsory use of the hijab within Iranian society, despite the fact that it is an online social movement that originated among the diaspora.

\section{The Significance of the Hijab Policy for Iranian Everyday Life}

Teheran in January, 2016. At the entrance of one of the most popular, modern shopping malls in Teheran, I saw the following warning signs. Highly amused, I was taking a photo of the hijab enforcement sign next to the "No pets" sign, when a mother and daughter passing by came to me and asked,

"What are you taking a photo of?" 
"I found it strange that there is a warning sign telling people to wear the hijab, next to one forbidding pets."

"That is reality in Iran. Women are always receiving warnings".

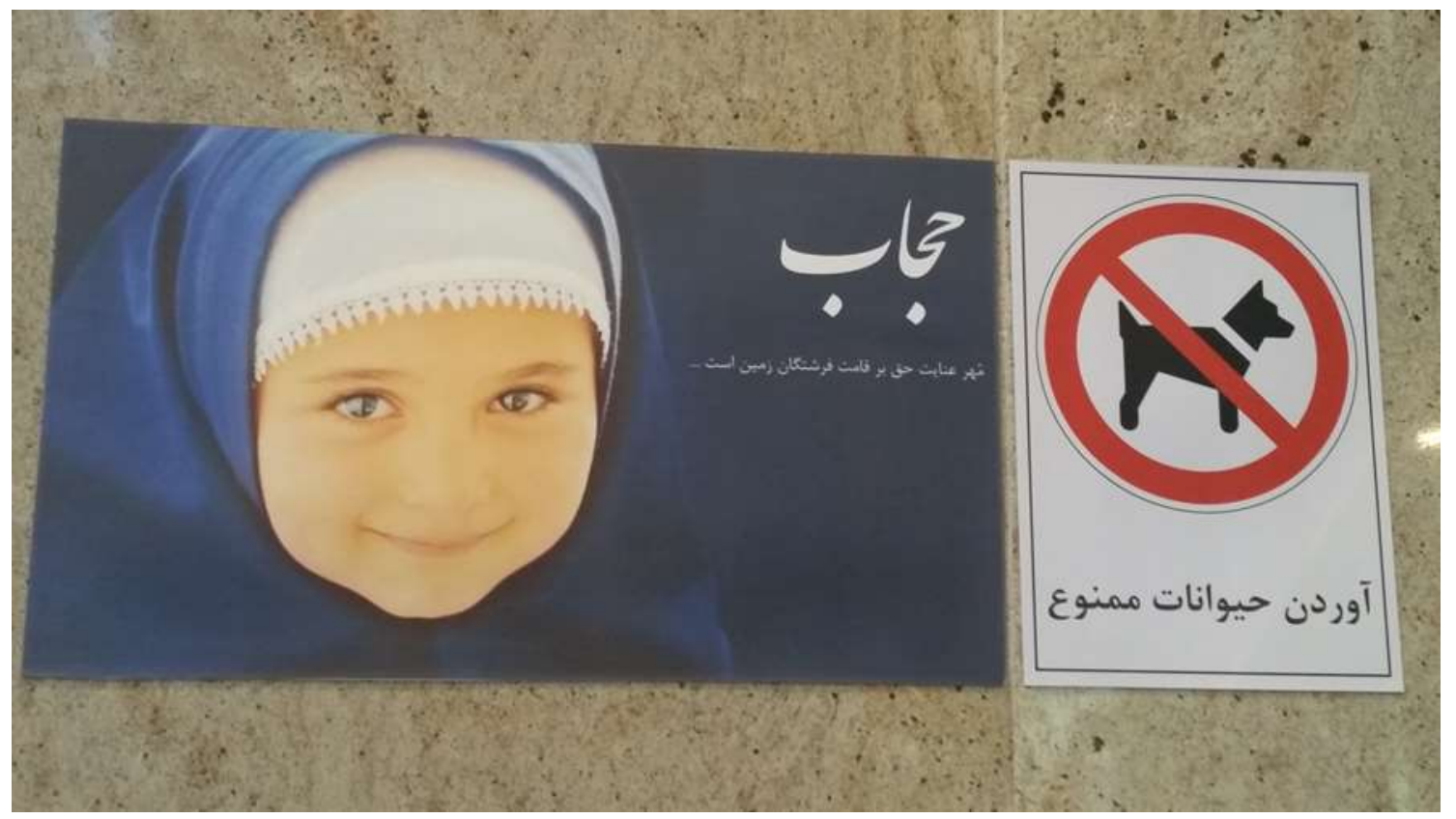

Fig. 1: A hijab-related warning sign next to a "No pets" sign at the entrance of a shopping center (Photo taken by the author in January, 2016).

In January 2016, economic sanctions on Iran were finally lifted and global market attention, particularly from Europe and East Asia, including China and Korea, was focused on Iran. President Hassan Rouhani has begun implementing various reforms, and Iran is taking slow steps toward becoming an internationally open market. However, policies regarding the compulsory use of the hijab for women remained unchanged, and periodic outfit controls continued to take place throughout the city. Nevertheless, I observed during my fieldwork women letting their long hair loose beneath their shawls and taking their hijabs off in their cars, letting them hang around their necks, as if in resistance to the official policies. Thus, in contemporary Iranian society, secular women have not just shown "stealthy" resistance by taking off their hijab and posting photos online, but have been disregarding Islamic regulations in their daily practices. To a certain extent, it is because of this history of hidden, yet daily, transgressions of Islamic restrictions that the hijab has remained a symbolic battlefield since the 1979 Islamic Revolution, and that "My Stealthy Freedom" has been able to gain so much support in and out of Iran.

However, in offline Iran, opinions on the hijab such as those expressed on "My Stealthy Freedom" have always been sharply opposed. Against this backdrop, the offline reception within Iran to "My Stealthy Freedom" cannot be the same as the online reception. As Vakil has explained, the hijab has a dynamic history and context in Iran and has always been a political issue (2011,67-69). Tahereh Ghoratolain, a member of the Baha'i movement, was executed for taking off her veil in 
public in 1848. The policy of unveiling in 1936 under Reza Shah and Islamic Revolution of 1979 brought back the issue of veiling. However, the hijab cannot be defined by a single voice in Iran's society, due to its context-dependency.

From the perspective of women's politics, the hijab is viewed differently than from a religious point of view. As a dynamic component of Iran, one must be very careful to take into account the hijab's cultural history when approaching the issue. Today, there is a high domestic awareness amongst Iranian women of the existence of "My Stealthy Freedom," and these women are slowly and carefully trying to claim their freedom.

According to research by Sean et al. (2014), social media affects people's behaviors in global settings like Iran that follow government-recommended cultural and religious traditions and behaviors (Sean et al. 2014). The offline, local reality has yet to fully reflect the online social movements. Khiabany (2015:230) attributes the limitations of this campaign to be "the mismatch between local context and concerns (internal) and the framing and reception of these concerns outside geographical boundaries of the local (external)." As Khiabany points out, the hijab is not the only problem women are facing in present-day Iranian society, and focusing only on this garment is an extremely Western, sexist point of view. For this reason, he maintains that we must be cautious of approaches that objectify Iranian women as victims that need to be freed from "pre-modern regulations" by taking off their veils. Iranian women are no longer passive agents of social movements, but rather, they have become the most active of subjects. As Vakil (2011: 213) explains, "The wheels of civil society continue to spin amidst political and social constraint and contradiction." In spite of government restrictions, the Iranian women's revolution "has come almost full circle" (Vakil 2011). Nevertheless, it is still important to criticize the problem surrounding the veil as it represents the lack of choice women face and their inability to make decisions for themselves. These women are posing the question, who makes the decisions for the freedom of whom?

It cannot be stated with absolute confidence that "My Stealthy Freedom" is as influential in offline Iran as it is online, nor that it is supported by Iranian women of all social classes. Yet the page is a clear testament that there is a large number of urban women with progressive inclinations within Iran who are against the government-driven hijab policy. The following two cases show how this online page is perceived at the local level in Iran and how it is entering into the daily discourse.

\section{Case 3. Local people (A and B )'s perception of 'My Stealthy Freedom' during 2015 fieldwork >}

Scene 1. January, 2015. Thirty-eight-year-old A did not care to fix her hijab, which had fallen, due to the wind as she drove her car across the city center. Neither did her fifteenyear-old daughter, B. With her smart phone in hand all day long, her hijab had fallen to her shoulders so that her long hair was showing, as she rode in her mother's car. Feeling nervous for her, I asked, "What if you get caught?" Her mother replied, "Have you heard of the Facebook page, 'My Stealthy Freedom'? While we cannot be completely free, we can enjoy 'stealthy freedom' at least inside my car."

Scene 2. While I was touring a hill looking over the Ancient Persian ruins of Persepolis, my guide, a man in his thirties, suggested taking a photo without my hijab. Sensing my hesitation, he reassured me, "It is okay if you are quick. Just like in 'My Stealthy Freedom.'” 
As can be clearly seen in <Case 3>, secular, upper middle-class Iranians in their twenties to forties, the daily users of social media, are well aware of "My Stealthy Freedom" and its contents. Furthermore, people who had been opposed to the compulsory enforcement of the hijab, even before the creation of this Facebook page, understand that "My Stealthy Freedom" symbolizes everyday resistance(Scott 2008) against the government repression of not just women's but all Iranians' freedom of choice. In other words, social media platforms are influencing the perception and political tendencies of the Iranian users. As mentioned above, the hijab issue for women was not first raised on the online platform in 2014, but rather, it was, and is, a social problem that Iranian women face in their day-to-day lives, as evident in <Case $4>$ below.

Case 4. July 15, 2015. Interview with a thirty-two-year-old, young female entrepreneur>

“Researcher: What do you think about women's compulsory use of the hijab?

Interviewee: Women have recently begun to raise different questions about the hijab. It is an influence of the Facebook page, "My Stealthy Freedom."

Researcher: Are Iranian women inside Iran well aware of this page?

Interviewee: Of course. Everybody knows of "My Stealthy Freedom." The government knows about this page too. Before this page was created, the government used the following propaganda: "All Iranian women love the hijab very much." However, people began to see the photos and messages shared on the page by Iranian women themselves, and the government has had to change its message to admit, "Most Iranian women support the hijab policy and enjoy wearing it, but there are some women who think otherwise."

The problem lies in the legal institutionalization of the use of the hijab. During the Islamic Revolution, Ayatollah Khomeini said that he would not enforce the use of the hijab on women. However, after the 1980 Iran-Iraq War, there was a movement in Iranian society to make the hijab compulsory. Then, in 1983, the compulsory hijab policy was enforced.

What is very ironic, though, is that amongst Islamic duties, praying is supposed to be more important than wearing the hijab. But, there is no legal regulation on praying, only on wearing the hijab. Perhaps, once the market opens and the economy is reinvigorated, things will get better. While it is unlikely that the current hijab policy is reversed from one day to another, perhaps they can lift the regulation at least for foreigners. Things need to change. It is ridiculous to impose wearing the hijab on all women. I once taught a course in a university, but after a semester, I was told, "You do not have the appropriate looks for this kind of job," and I was fired. In order to have such a public job, one needs to wear a chador, the most conservative kind of hijab.

As seen in <Case 4>, since the compulsory use of the hijab was enforced in 1983, to this day there has been no change in the policy, and the government continues its daily acts of censorship and repression. According to the Iranian traffic police, the police stopped tens of thousands of cars during eight months in 2015, of which forty thousand were due to "cases of bad hijab." The reason for this kind of road control is because, as seen above, women have been driving on the highways without wearing their hijab properly or dressing "inappropriately" on their ways to parties and social gatherings. Thus, one of the duties of the traffic police in Iran, along with stopping cars for 
speeding or infringement of traffic regulations, is controlling women's hijabs and outfits (Withnall 2015).

Compared to the Ahmadinejad era that emphasized strong conservative Islamization, the hijab policy has been much relaxed during the Rouhani period. Even so, the use of the hijab still remains compulsory and some women still hesitate to leave their homes for fear of the Basij and undercover police who abuse them verbally to wear their russaris properly. While women generally wear their hair below their russaris, in shopping malls, there are announcements every ten minutes telling women to fix their hijabs. According to an Iranian police spokesman, in 2014 the police obtained 207,053 pledges from norm-breakers (women caught for not wearing their hijab properly) to observe the law, referred 18,081 cases to the Judiciary, and gave warnings to 2,917,000 other norm-breakers (Amnesty International 2015).

Furthermore, resistance against the hijab policy in women's daily lives does take place, albeit mostly online. For example, on February 9th, 2016 an application called "Gershad" was launched, enabling users to track the location of the Gasht-e-Ershad (or Guidance Patrol, commonly known as the "morality police") on a digital map of Tehran.

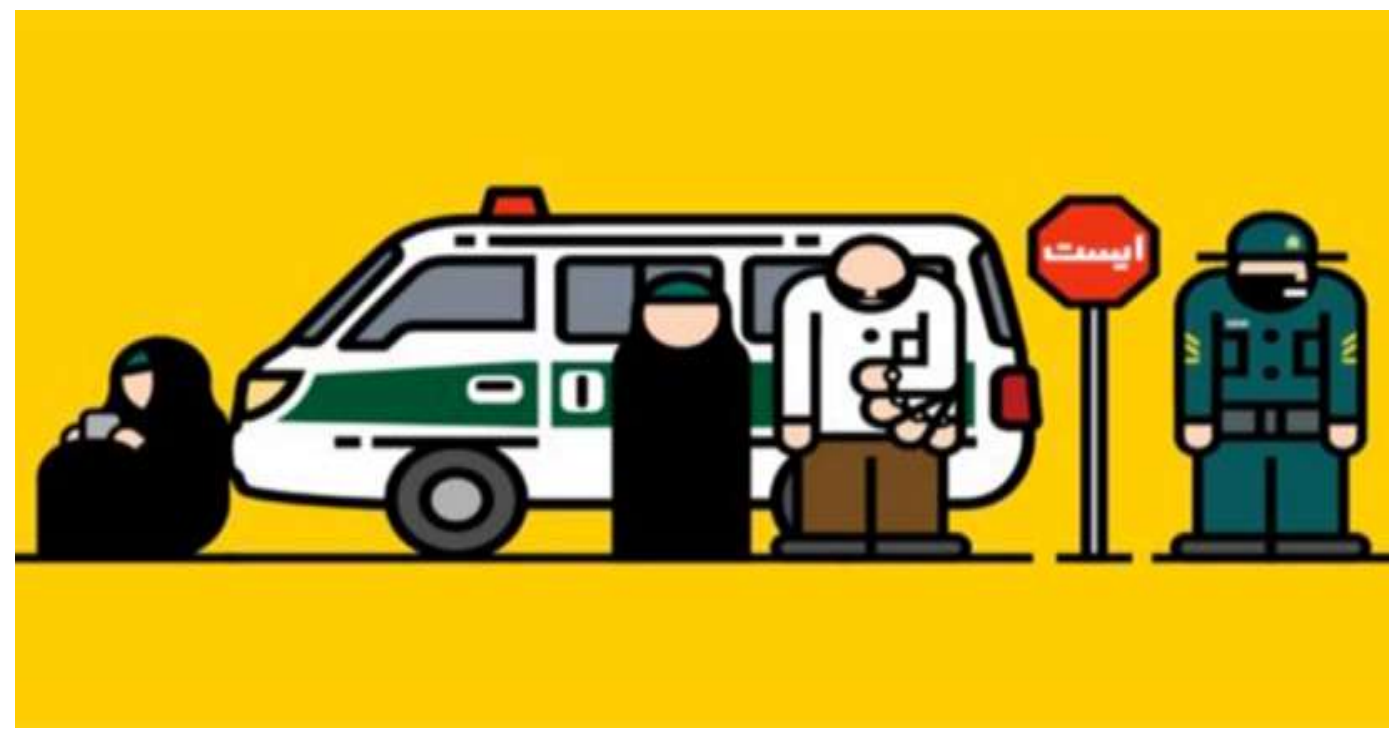

Fig 2: http://www.gershad.com

As soon as this application was released, numerous people downloaded it, although it was blocked in Iran within 24 hours. This application is one example of how the new technology can be used in defiance of the government's regulations. This kind of application and such an explosive response shows the kind of hide-and-seek game going on between the State and the Iranian women in their daily lives. Furthermore, it is evidence of how the Iranian people are discretely or stealthily struggling against the politics of what has come to be called the reign of terror.

Nonetheless, since I began carrying out short and long-term fieldwork concerning the qualitative assessment of women's social positions and the implementation of Islamic regulations in the public sphere in 2002, there have been visible transformations in the perception of the hijab in Iranian society (Koo 2013, 2014). Particularly, since Hassan Rouhani assumed the presidency, women's choices and manner of wearing the hijab have noticeably changed. It is clear that Iranian society is undergoing change, albeit very slowly, and even the Iranian government is aware of the feminist movements that are taking place not only inside Iran, but worldwide in cyberspace. 


\section{Conclusion}

Iran is undergoing much change in the international and national scene, since the economic sanctions were lifted in 2016, and since President Rouhani has come into power. It can be said that studying the historical and social steps towards the recognition of Iranian women's gender rights, in particular regarding the hijab policy, will be important not only within the context of the hijab policy, but also to understand the trajectory of women's social movements in Iran.

The objective of this article has been to understand the significance of political movements in the digital domain and the trends in Iranian social movements through an analysis of Iranian women's social movements on global social media. With the resolution of the Iranian nuclear negotiations, Iran's political and economic role on the international stage has become more important than ever. These negotiations have led to a rapid opening of the markets and there are high expectations for more internal changes in Iranian society. Leading the resistance against the compulsory use of the hijab, "My Stealthy Freedom" is currently (as of April, 2016) leading a campaign under the hashtag \#SeeYoulnIranWithoutHijab, in which it calls for foreign women visiting Iran to support their cause and suggests that they too remove their hijab. Their statement reads:

\footnotetext{
"We are calling on all female tourists visiting Iran to come and support the refusal of stewardesses working for Air France to wear the veil on flights once they are in Iran. We are also asking them to support the 'My Stealthy Freedom' Campaign. As a sign of support, here is what you can do: when you visit our beautiful Iran, you can take a photo without the compulsory headscarf as a sign of protest and send it to this campaign. On this Facebook page, you will see lots of such photos taken by Iranian women inside Iran. Please be as brave as them and say no to a discriminatory law. Women must have the right to choose how they dress".
}

This movement did not bring the anticipated result, which was freedom of foreign women from obligation to wear hijab. But \#SeeYoulnIranWithoutHijab campaign did reinforce the importance of the problem, by extending the problem to women from other countries beyond Iranian women and thus bringing the hijab discourse to a more global sphere. On April 7, 2016, the founder and administrator of "My Stealthy Freedom," Masih Alinejad, took the stage at the Women in the World New York Summit and said the following: "Women in Iran are breaking the law every day just to be themselves. And I'm a master criminal because the government thinks I have too much hair, too much voice, and I am too much of a woman." As Alinejad pointed out, the secular women in Iranian society need to wear a thick mask in their quest to find their true "selves," and if they wish to reveal themselves, they must submit to numerous dangers (Koo 2013).

It is true that there are still many women in Iranian society who choose, of their own will, to retain the image of the hijab and wear the most conservative type of hijab. Furthermore, it cannot be said that the women participating in this stealthy movement of removing their hijab are the majority. However, this online movement finds its value in that it has become a new platform for women to raise their voices in the public sphere. In contemporary Iranian society, the hijab is one of the most political devices as it transcends a mere Islamic garment and holds symbolic significance, representing one of the greatest political struggles between the reformists and the conservatives (Koo 2014). 
Koo, To be Myself and have My Stealthy Freedom...

\section{Bibliography}

AKHAVAN, Niki (2013): Electronic Iran-The Cultural Politics of an Online Evolution. Rutgers University Press.

Amnesty International Ltd (2015): You Shall Procreate: Attacks on Women's Sexual and Reproductive Rights in Iran, Peter Benenson House, United Kingdom.

ARENDT, Hannah (1998): The Human Condition, 2nd Edition, The University of Chicago Press.

BAYAT, A. (2005): "Islamism and social movement theory" in Third World Quarterly, 26(6), 891908. https://doi.org/10.1080/01436590500089240

BAYAT, Asef (2013): Life as politics: How ordinary people change the Middle East. Stanford University Press.

BENHABIB, Seyla (1992): Situating the self: Gender, community and postmodernism in contemporary ethics. Psychology Press.

BEKKERS, Victor, et al. (2001): "New media, micromobilization, and political agenda setting: Crossover effects in political mobilization and media usage" in The Information Society, 27.4: 209219.

EL-NAWAWY, Mohammed; KHAMIS, Sahar (2013): Egyptian revolution 2.0: Political blogging, civic engagement, and citizen journalism. Palgrave Macmillan.

ELORANTA Jari, KERMANI Hossein and RAHIMI Babak (2015): "Facebook Iran: Social Capital and the Iranian Social Media", FARIS, David M.; RAHIMI, Babak (ed.), Social media in Iran: Politics and society after 2009. SUNY Press.

FARIS, David M.; RAHIMI, Babak (ed.). (2015): Social media in Iran: Politics and society after 2009. SUNY Press.

GARRETT, Kelly R. 2006): "Protest in an information society: A review of literature on social movements and new ICTs". Information, communication \& society, 9.02: 202-224. https://doi.org/10.1080/13691180600630773

GHEYTANCHI Elham (2015): "Gender Roles in Social Media World of Iranian Women", in FARIS, David M.; RAHIMI, Babak (ed.), Social media in Iran: Politics and society after 2009. SUNY Press.

GOULD, Rebecca (2014): "Hijab as commodity form: Veiling, unveiling, and misveiling in contemporary Iran" in Feminist Theory, vol.15, no.3, pp.221-240. https://doi.org/10.1177/1464700114544610

HAMZEHEI, Pegah (2014): Iranian Women's Experience of Mandatory Hijab: A Case Study of a Campaign on Facebook. Independent thesis Advanced level, Stockholm University, Faculty of Humanities, Department of Media Studies.

HAJINEJAD, Mona (2009): Gender representation of youth in an online social networking site. Visual analysis of Iranian youth on facebook profile picture, Master's thesis, Stockholm University, Sweden.

HARAWAY, Donna (1991): Simians, Cyborgs, and women: The reinvention of women. London and New York: Routledge.

HARLOW, Summer and HARP, Dustin (2012): "Collective action on the Web: A cross-cultural study of social networking sites and online and offline activism in the United States and Latin America. Information" in Communication \& Society, 15.2: 196-216. https://doi.org/10.1080/1369118X.2011.591411

KARIMI, Sedigheh (2014): "Iranian Women's Identity and Cyberspace: Case study of Stealthy Freedom" In Journal of Social Science Studies, vol.2, no.1

KOO, Gi Yeon (2013): Making their own world: Emotion and self among the privileged Iranian youth. Doctoral Dissertation of Anthropology, Seoul National University, Seoul. 
KOO, Gi Yeon (2014): "Women as Subject of Defiance and Everyday Politics of Hijab as Dress Code in Modern Iran" in Asian Women, vol. 30, no. 4, pp. 29-51. https://doi.org/10.14431/aw.2014.12.30.4.29

KHIABANY, Gholam (2015): "The Importance of 'Social' in Social Media: Lessons from Iran". The Routledge Companion to Social Media and Politics, Edited by CHRISTENSEN, Christian, et al., Routledge, pp. 223-234.

LERNER, Melissa (2010): "Connecting the actual with the virtual: The Internet and social movement theory in the Muslim world-The cases of Iran and Egypt" in Journal of Muslim Minority Affairs 30.4): 555-574. https://doi.org/10.1080/13602004.2010.533453

LEWIS, Reina (2015): "Uncovering Modesty: Dejabis and Dewigies Expanding the Parameters of the Modest Fashion Blogosphere" in Fashion Theory, vol.19, no. 2, pp. 243-269. https://doi.org/10.2752/175174115X14168357992472

NOVAK, Alison N., and EMAD Khazraee (2014): "The Stealthy Protester: Risk and the Female Body in Online Social Movements" in Feminist Media Studies, vol.14, no.6, pp. 1094-1095. https://doi.org/10.1080/14680777.2014.975438

PLANT, Sadi (2000): On the matrix: Cyberfeminist simulations. The cybercultures reader, pp. 325336.

RAHAGHI, John (2012): "New tools, old goals: Comparing the role of technology in the 1979 Iranian Revolution and the 2009 Green Movement" in Journal of Information Policy, 2: 151-182. https://doi.org/10.5325/jinfopoli.2.2012.0151

SCOTT, Alan, and John STREET (2000): "From media politics to e-protest" in Information, Communication \& Society 3.2 , pp. 215-240. https://doi.org/10.1080/13691180050123712

SCOTT, James (2008): Weapons of the weak: Everyday forms of peasant resistance. Yale university Press.

SEMATI, Mehdi (ed.) (2007): Media, culture and society in Iran: living with globalization and the Islamic state. Routledge.

SHIRKY, Clay (2001): "The political power of social media" in Foreign affairs, 90.1: 28-41.

SREBERNY, Annabelle (2015): "Women's Digital Activism in a Changing Middle East" In International Journal of Middle East Studies, vol.47, no.2, pp.357-361. https://doi.org/10.1017/S0020743815000112

SREBERNY, Annabelle \& Khiabany, G. (2010): Blogistan: The internet and politics in Iran , vol.18, IB Tauris.

SREBERNY, Annabelle \& Torfeh, M. (Eds.). (2013): Cultural revolution in Iran: contemporary popular culture in the Islamic Republic. IB Tauris.

YAGHMAIAN, Behzad (2002): Social change in Iran: An eyewitness account of dissent, defiance, and new movements for rights. SUNY Press.

YAHYANEJAD, Mehdi (2015): "The Role of Social Media: Myth and Reality", in MILANI, Abbas; DIAMOND, Larry Jay (ed.). Politics and culture in contemporary Iran: challenging the status quo. Lynne Rienner Publishers.

YOUNG, Sean D., et al (2014): "The Influence of Social Networking Technologies on Female Religious Veil-Wearing Behavior in Iran", Cyberpsychology, Behavior and Social Networking, vol. 17 , no. 5, 317-321.

VAKIL, Sanam (2011): Women and politics in the Islamic republic of Iran: Action and reaction. Bloomsbury Publishing USA.

VAN LAER, Jeroen; VAN AELST, Peter (2010): "Internet and social movement action repertoires: Opportunities and limitations" in Information, Communication \& Society, 13.8: 1146-1171. https://doi.org/10.1080/13691181003628307 
ZAHEDI, Ashraf (2007): "Contested meaning of the veil and political ideologies of Iranian regimes" in Journal of Middle East Women's Studies, 2007, 3.3: 75-98. https://doi.org/10.1215/155258642007-4004

\section{Online Sources}

https://www.facebook.com/StealthyFreedom. Cover photo posted on May 19th, 2014 (https://www.facebook.com/StealthyFreedom/photos/a.858877157459713.1073741827.8588328 00797482/871101186237310/?type=3\&theater) [access: 3 March 2014].

Allison Maloney, "Masih Alinejad: "Women in Iran are breaking the law every day just to be ourselves", http://nytlive.nytimes.com/womenintheworld/2016/04/07/masihalinejad/[access: 8 April 2016].

Adam Withnall, "Thousands of women in Iran have cars impounded for 'not wearing hijab properly'", INDEPENDENT, Wednesday $16 \quad$ December 2015. http://www.independent.co.uk/news/world/middle-east/thousands-of-women-in-iran-have-carsimpounded-for-not-wearing-hijab-properly-a6774366.html /[access: 23 August 2016].

"Iranian actress 'branded immoral' for posting pictures without hijab," The Telegraph, (http://www.telegraph.co.uk/news/worldnews/middleeast/iran/11964644/Iranian-actressbranded-immoral-for-posting-pictures-without-hijab.html) [access: 8 March 2016].

Marjohn Sheikhi , 31, Aug, 2016, "Controversy of female cyclists in Iran: To cycle not to cycle", http://en.mehrnews.com/news/119318/To-cycle-or-not-to-cycle-Controversy-of-female-cyclistsin-Iran

"Bad Hijab App is Blocked" (https://exposingiransite.wordpress.com/2016/02/09/bad-hijab-appis-blocked/) 